\title{
El Órgano Administrativo de Recursos Contractuales de la Comunidad Autónoma de Euskadi y los órganos colegiados de los Territorios Históricos
}

\author{
Ramón Terol Gómez \\ Profesor Titular de Derecho Administrativo \\ Universidad de Alicante \\ ramon.terol@ua.es
}

\begin{abstract}
Resumen
Fruto de la modificación del régimen de recursos en materia de contractos por la Ley 34/2010, de reforma de la Ley 30/2007, de Contratos del Sector Público, y de la Ley 31/2007, de contratos en los sectores del agua, la energía, los transportes y los servicios postales, se han ido creando en las Comunidades Autónomas órganos independientes y especializados para la resolución de tales recursos en su ámbito de competencias. En el presente trabajo nos ocuparemos del régimen de organización y funcionamiento de los órganos que a tal fin se han creado en la Comunidad Autónoma de Euskadi y que es el Órgano Administrativo de Recursos Contractuales. Órgano que convive con los correspondientes que se han creado también y previamente en los Territorios Históricos de Álava, Bizkaia y Gipuzkoa, que serán objeto de nuestra atención.
\end{abstract}

Palabras clave Recursos administrativos, recurso especial en materia de contratación, Tribunal Administrativo Foral de recursos contractuales del Territorio Histórico de Gipuzkoa, Tribunal Administrativo Foral de recursos contractuales del Territorio Histórico de Bizkaia, Órgano Administrativo Foral de Recursos Contractuales de Álava, Órgano Administrativo de Recursos Contractuales de la Comunidad Autónoma de Euskadi

\section{The Public Procurement Review Administrative Authority of the Autonomous Region of Euskadi and the collegiate bodies of the Historical Territories}

\begin{abstract}
As a result of the change in the contract review system under Law 34/2010, which amends Law 30/2007, on Public Sector Contracts, and Law 31/2007, on contracts in the water, power, transport and postal services sectors, independent bodies specialised in settling disputes within their respective spheres of competence have been created in the autonomous regions. In this paper we address the organisation and functioning system of the bodies created for this purpose in the Autonomous Region of Euskadi, which is the Public Procurement Review Administrative Authority. This authority coexists with previously created bodies in the Historical Territories of Alava, Bizkaia and Gipuzkoa, which will be the focus of our attention.
\end{abstract}

Key words

Administrative reviews, special public procurement review, Public Procurement Review Administrative Court of the Historical Territory of Gipuzkoa, Public Procurement Review Administrative Court of the Historical Territory of Bizkaia, Public Procurement Review Administrative Authority of Alava, Public Procurement Review Administrative Authority of the Autonomous Region of Euskadi. 


\section{CONSIDERACIONES GENERALES SOBRE LAS COMPETENCIAS DE LA COMUNIDAD AUTÓNOMA DE EUSKADI Y DE LOS TERRITORIOS HISTÓRICOS EN MATERIA DE CONTRATACIÓN Y LA REFORMA DEL RÉGIMEN DE RECURSOS CONTRACTUALES POR LA LEY 34/2010 EN EL PLANO ORGÁNICO.}

No es preciso insistir en que la contratación pública es una de las materias que, en lo que al establecimiento de la legislación básica se refiere, corresponde en exclusiva al Estado ex artículo 149.1.18 de la Constitución -"legislación básica sobre contratos”-, correspondiendo a las Comunidades Autónomas su desarrollo y ejecución. Cuestión esta que no implica mayores problemas en el caso de la Comunidad Autónoma de Euskadi cuyo Estatuto de Autonomía, contenido en la Ley Orgánica 3/1979, de 18 de diciembre, establece en su artículo 11.1 que "es de competencia de la Comunidad Autónoma del País Vasco el desarrollo legislativo y la ejecución dentro de su territorio de la legislación básica del Estado en las siguientes materias: b) ... contratos y concesiones administrativas, en el ámbito de sus competencias ...".

En el caso de Euskadi, hay que tener en cuenta además la existencia de los Territorios Históricos, como entidades peculiares amparadas por la Disposición Adicional Primera de la Constitución, cuando establece que la misma "ampara y respeta los derechos históricos de los territorios forales. La actualización general de dicho régimen foral se llevará a cabo, en su caso, en el marco de la Constitución y de los Estatutos de Autonomía", lo que implica contar con instituciones de autogobierno en forma de Juntas Generales y Diputaciones Forales, recogiéndose estas entidades en el Estatuto de Autonomía antes señalado, y dando lugar posteriormente a la aprobación de la fundamental Ley $27 / 1983$, de 25 de noviembre, de Relaciones entre las Instituciones Comunes de la Comunidad Autónoma y de los Órganos Forales de sus Territorios Históricos. Además, la resolución de los conflictos de competencias entre la Comunidad Autónoma y los órganos forales se encomienda a una Comisión Arbitral que prevista el Estatuto está regulada en la Ley 13/1994, de 30 de junio.

No nos extendernos sobre la peculiar organización política de la Comunidad Autónoma de Euskadi y sus instituciones de autogobierno', pues con creces excede del objeto del presente trabajo, en el que limitándonos a constatar las competencias que tan-

1 Sobre esta cuestión, nos remitimos, por todos, al ya clásico trabajo de Fernández Rodríguez, T.R., Los Derechos Históricos de los Territorios Forales, CEC-Civitas, Madrid, 1985 y el de Muñoz Machado, S., El problema de la vertebración del Estado en España (Del siglo XVIII al siglo XXI), lustel, Madrid, 2006, así como los de Castells Arteche, J.M., “El hecho diferencial Vasco” y Jiménez Asensio, R., "El sistema de fuentes del Derecho de la Comunidad Autónoma del País Vasco como ordenamiento asimétrico", ambos en Revista Vasca de Administración Pública, n 47-II (1997), págs. 113 a 126 y 127 a 171, respectivamente.

También se refiere a ello Muñoz Machado, S. en sus trabajos Derecho Público de las Comunidades Autónomas, Tomo I, $2^{\text {a }}$ ed., lustel, Madrid, 2007, págs. 52 y ss, y Tratado de Derecho Administrativo y Derecho Público General, Tomo III, lustel, Madrid, 2009, especialmente págs. 195 y ss., y Larrazabal Basañez, S., “¿26 años no es nada...? Luces y sombras en la distribución de competencias entre las instituciones Comunes de la Comunidad Autónoma del País Vasco y las de sus Territorios Históricos", Revista Vasca de Administración Pública, n 87-88 (2010), págs. 707 a 741. 
to la Comunidad Autónoma como los Territorios Históricos ostentan en materia de contratación, abordaremos el estudio de los órganos que recientemente se han creado en sus respectivos ámbitos para conocer de los recursos especiales en esta materia, de acuerdo con lo dispuesto en la Ley 34/2010, de 5 de agosto, de modificación de las Leyes 30/2007, de 30 de octubre, de Contratos del Sector Público, 31/2007, de 30 de octubre, sobre procedimientos de contratación en los sectores del agua, la energía, los transportes y los servicios postales, y 29/1998, de 13 de julio, reguladora de la Jurisdicción Contencioso-Administrativa para la adaptación a la normativa comunitaria de las dos primeras. Órganos como estos, hay por lo menos que reseñarlo ahora, se han constituido en cumplimiento de la señalada normativa tanto en el Estado -Tribunal Administrativo Central de Recursos Contractuales² - como en otras Comunidades Autónomas ${ }^{3}$.

Norma esta, la Ley 34/2010, que trajo causa de la transposición al ordenamiento español de la Directiva 2007/66/CE, de 11 de diciembre, por la que se modifican las Directivas $89 / 665 /$ CEE y $92 / 13 /$ CEE del Consejo en lo que respecta a la mejora de la eficacia de los procedimientos de recurso en materia de adjudicación de contratos públicos, cuyo plazo de incorporación a los ordenamientos nacionales expiró el 20 de diciembre de 2009, pudiendo afirmarse una incorporación tardía al nuestro con la consiguiente reacción de las autoridades comunitarias ${ }^{4}$.

No abordaremos tampoco el régimen del recurso especial en materia de contratación ni la acción de nulidad5, que se establecen y perfilan con la Ley 34/2010 y que

2 Al mismo se refiere, por todos, la monografía de Pulido Quecedo, M., El Nuevo Tribunal Administrativo Central de Recursos Contractuales, Aranzadi Thomson Reuters, Navarra, 2010.

3 Sobre ello versa el trabajo de Bernal Blay, M.A., "Aspectos orgánicos del recurso especial en materia de contratación pública en las Comunidades Autónomas", Cuadernos de Derecho Local, $n^{\circ} 26$ (2011), págs. 7 a 26. Puede consultarse también Parejo Alfonso, L., “La revisión especial de actos en la legislación de contratos del sector público”, El nuevo marco de la contratación pública (Parejo, L. y Palomar, A., Dirs.), Bosch, Barcelona, 2012, págs. 222 y ss.

4 En general, sobre la Ley 34/2010, puede verse la monografía de Moreno Molina, J.A., La reforma de la Ley de Contratos del Sector Público en materia de recursos. Análisis de la Ley 34/2010, de 5 de agosto, la Ley, Madrid, 2010, y del mismo autor "La Ley 34/2010 y al adaptación en España del derecho de la Unión Europea en materia de recursos en los procedimientos de adjudicación de contratos públicos", Revista General de Derecho Administrativo, n² 25 (2010), págs. 1 a 30, y “Las últimas reformas de la LCSP y en especial la Ley 34/2010, de 5 de agosto, de modificación de la LCSP, la Ley de Contratos en los Sectores Especiales y la Ley de la Jurisdicción Contencioso Administrativa", Contratación Administrativa Práctica, n 102 (2010), págs. 3 a 32. También Gallego Córcoles, I., “Comentario a la Ley 34/2010, de 5 de agosto, de modificación de las Leyes 30/2007, de 30 de octubre, de Contratos del Sector Público, 31/2007, de 30 de octubre, sobre procedimientos de contratación en los sectores del agua, la energía, los transportes y los servicios postales, y 29/1998, de 13 de julio, reguladora de la Jurisdicción Contencioso-Administrativa para adaptación a la normativa comunitaria de las dos primeras", Contratación Del Sector Público Local, $2^{\text {a }}$ ed., La Ley-El Consultor, Madrid, 2010, págs. XIX a LXXIII, y Cortés Moreno, A., “La adaptación de la Ley 30/2007, de 30 de octubre, de Contratos del Sector Público a la Directiva 2007/66/CE realizada por la Ley 34/2010, de 5 de agosto", El Consultor de los Ayuntamientos y de los Juzgados, n²4, Sección Actualidad, Quincena del 30 diciembre 2010 al 14 enero 2011, págs, 3456 y ss.

5 Sobre lo que contamos con importantes aportaciones, contenidas principalmente en los trabajos de Palomar Olmeda, A., “La nulidad de los contratos y la nueva acción de nulidad”, y Parejo Alfonso, L., "La revisión especial de actos en la legislación de contratos del sector público", ambos en El nuevo marco de la contratación pública (Parejo, L. y Palomar, A., Dirs.), Bosch, Barcelona, 2012, págs. 141 a 198 y 199 a 240, res- 
serán la competencia sustantiva primordial de los órganos que serán objeto de nuestra atención.

Y es que en este ámbito, el de la contratación pública, concurren, además de su natural complejidad, un nítido componente de inseguridad dada la usual transposición tardía de Directivas comunitarias ${ }^{6}$ así como diversas reformas introducidas por ello y por otras circunstancias derivadas de modificar este marco jurídico a fin de -entre otras motivaciones- afrontar la crisis económica mediante la aprobación de normas al efecto?.

Tanto es así, que una Ley tan reciente como la Ley 30/2007, de 30 de octubre, de Contratos del Sector Público (LCSP) ya en 2010 llevaba un número tan importante de modificaciones, que la Disposición Final $32^{\text {a }}$ de la Ley 2/2011, de 4 de marzo, de Economía Sostenible, autorizaba al Gobierno "para elaborar, en el plazo de un año a partir de la entrada en vigor de esta Ley, un texto refundido en el que se integren, debidamente regularizados, aclarados y armonizados, la Ley 30/2007, de 30 de octubre, de Contratos del Sector Público, y las disposiciones en materia de contratación del sector público contenidas en normas con rango de Ley, incluidas las relativas a la captación de financiación privada para la ejecución de contratos públicos", dando lugar así a la aprobación del Real Decreto Legislativo 3/2011, de 14 de noviembre, por el que se aprueba el Texto Refundido de la Ley de Contratos del Sector Público (TRLCSP), y con ello a la derogación de la LCSP.

Sin que sea preciso afirmar ahora las competencias de la Comunidad Autónoma de Euskadi en materia de contratación, la de los Territorios Históricos venía expresamente recogida en la ya derogada Disposición Adicional $33^{\text {a }}$ LCSP, bajo la rúbrica de "Régimen de contratación de los órganos de los Territorios Históricos del País Vasco", donde establecía que "las Diputaciones Forales y las Juntas Generales de los Territorios Históricos del País Vasco ajustarán su contratación a las normas establecidas en esta Ley para las Administraciones Públicas".

Proposición normativa esta que ha sido sustituida por lo que ahora establece el artículo 3.2.g) TRLCSP: “2. Dentro del sector público, y a los efectos de esta Ley, ten-

\footnotetext{
pectivamente; Razquin Lizarraga, M.M., "El sistema especial de recursos en la contratación pública tras la reforma de la Ley de Contratos del Sector Público", Revista General de Derecho Administrativo, nº 25 (2010), págs. 1 a 54; Canales Gil. A. y Huerta Barajas, J.A., La contratación del sector público tras las reformas de 2010, Reus, Madrid, 2010, págs. 431 y ss., y Gimeno Feliu, J.M., "El nuevo sistema de recursos en materia de contratos públicos", Observatorio de Contratos Públicos 2010, Aranzadi Civitas, Navarra, 2010, págs. 211 y ss.

6 Por todos, vid. Moreno Molina, J.A., "La falta de adecuación de la Ley española de Contratos del Sector Público al Derecho Comunitario Europeo", Monografía de la Revista Aragonesa de Administración Pública (Agua, territorio, cambio climático y Derecho Administrativo), n XI (2009), págs. 337 a 353.

7 A las reformas introducidas en la LCSP en 2010 se dirige la monografía de Canales Gil, A. y Huerta Barajas, J.A., La contratación del sector público tras las reformas de 2010, op. cit., y la obra colectiva EI nuevo marco de la contratación pública (Parejo, L. y Palomar, A., Dirs.), Bosch, Barcelona, 2012.

8 Sobre esta disposición puede verse, por todos, Entrena Ruiz, D., "Disposición Adicional Trigési-
} 210 mo Tercera", Comentarios a la Ley de Contrato 
drán la consideración de Administraciones Públicas los siguientes entes, organismos y entidades: ... g) Las Diputaciones Forales y las Juntas Generales de los Territorios Históricos del País Vasco en lo que respecta a su actividad de contratación". Norma esta que tanto el Consejo de Estado ${ }^{9}$ como la doctrina ${ }^{10}$ consideran equivalente a la Adicional $33^{\mathrm{a}}$ derogada de la LCSP.

El precepto de carácter básico que sirve de referente a la hora de que tanto la Comunidad Autónoma como los Territorios Históricos afronten la regulación del órgano administrativo que haya de conocer de los recursos en materia de contratación es el artículo 41 TRLCSP, coincidente en su textualidad con el 311 LCSP con la redacción que dio al mismo la mencionada Ley 34/2010. Este es su tenor literal, por lo que a los efectos de este trabajo interesa, a partir del apartado 3 del mismo:

“3. En el ámbito de las Comunidades Autónomas, así como en el de los órganos competentes de sus Asambleas Legislativas y de las instituciones autonómicas análogas al Tribunal de Cuentas y al Defensor del Pueblo la competencia para resolver los recursos será establecida por sus normas respectivas, debiendo crear un órgano independiente cuyo titular, o en el caso de que fuera colegiado al menos su Presidente, ostente cualificaciones jurídicas y profesionales que garanticen un adecuado conocimiento de las materias de que deba conocer. El nombramiento de los miembros de esta instancia independiente y la terminación de su mandato estarán sujetos en lo relativo a la autoridad responsable de su nombramiento, la duración de su mandato y su revocabilidad a condiciones que garanticen su independencia e inamovilidad.

Las Comunidades Autónomas podrán prever la interposición de recurso administrativo previo al contemplado en el artículo 40.

En este último caso, la ejecución de los actos de adjudicación impugnados quedará suspendida hasta que el órgano competente para resolverlo decida sobre el fondo de la cuestión planteada. En todo caso, si la resolución no fuese totalmente estimatoria, la suspensión persistirá en los términos previstos en el artículo 45.

Podrán las Comunidades Autónomas, asimismo, atribuir la competencia para la resolución de los recursos al Tribunal especial creado en el apartado 1 de este ar-

9 Vid. su Dictamen 1748/2011, de 3 de noviembre, al Proyecto de Real Decreto Legislativo por el que se aprueba el Texto Refundido de la Ley de Contratos del Sector Público, donde se afirma:

“... En el artículo 3.2 relativo a qué entes del sector público tienen la consideración de Administraciones públicas a efectos de esta ley, se incluyen los apartados f) y g), relativos respectivamente a los órganos constitucionales del Estado y los órganos legislativos y de control autonómicos, y a las Diputaciones Forales y las Juntas Generales de los Territorios Históricos del País Vasco (consideración que ya tenían ambos grupos de entidades a tenor de la redacción de las disposiciones adicionales tercera y trigésimo tercera de la LCSP, en su redacción en ambos casos por la Ley 34/2010, de 5 de agosto, de modificación de las Leyes 30/2007, de 30 de octubre, de Contratos del Sector Público, 31/2007, de 30 de octubre, sobre procedimientos de contratación en los sectores del agua, la energía, los transportes y los servicios postales, y 29/1998, de 13 de julio, reguladora de la Jurisdicción Contencioso-administrativa, para adaptación a la normativa comunitaria de las dos primeras [abreviadamente, Ley 34/2010])".

10 Vid. por todos Moreno Molina, J.A. y Domínguez Alonso, A.P., "Suma y sigue, el Real Decreto Legislativo 3/2011, de 14 de noviembre, por el que se aprueba el Texto Refundido de la Ley de Contratos del Sector Público", Diario La Ley, n 7772 (2012). 
tículo. A tal efecto, deberán celebrar el correspondiente convenio con la Administración General del Estado, en el que se estipulen las condiciones en que la Comunidad sufragará los gastos derivados de esta asunción de competencias.

Las Ciudades Autónomas de Ceuta y Melilla podrán designar sus propios órganos independientes ajustándose a los requisitos establecidos en este apartado para los órganos de las Comunidades Autónomas, o bien atribuir la competencia al Tribunal Administrativo Central de Recursos Contractuales celebrando al efecto un convenio en los términos previstos en el párrafo anterior.

4. En el ámbito de las Corporaciones Locales, la competencia para resolver los recursos será establecida por las normas de las Comunidades Autónomas cuando éstas tengan atribuida competencia normativa y de ejecución en materia de régimen local y contratación.

En el supuesto de que no exista previsión expresa en la legislación autonómica, la competencia corresponderá al mismo órgano al que las Comunidades Autónomas en cuyo territorio se integran las Corporaciones Locales hayan atribuido la competencia para resolver los recursos de su ámbito.

5. Cuando se trate de los recursos interpuestos contra actos de los poderes adjudicadores que no tengan la consideración de Administraciones Públicas, la competencia estará atribuida al órgano independiente que la ostente respecto de la Administración a que esté vinculada la entidad autora del acto recurrido.

Si la entidad contratante estuviera vinculada con más de una Administración, el órgano competente para resolver el recurso será aquél que tenga atribuida la competencia respecto de la que ostente el control o participación mayoritaria y, en caso de que todas o varias de ellas, ostenten una participación igual, ante el órgano que elija el recurrente de entre los que resulten competentes con arreglo a las normas de este apartado.

6. En los contratos subvencionados a que se refiere el último inciso del artículo 40.1 de esta Ley, la competencia corresponderá al órgano independiente que ejerza sus funciones respecto de la Administración a que esté adscrito el ente u organismo que hubiese otorgado la subvención, o al que esté adscrita la entidad que la hubiese concedido, cuando ésta no tenga el carácter de Administración Pública. En el supuesto de concurrencia de subvenciones por parte de distintos sujetos del sector público, la competencia se determinará atendiendo a la subvención de mayor cuantía y, a igualdad de importe, al órgano ante el que el recurrente decida interponer el recurso de entre los que resulten competentes con arreglo a las normas de este apartado".

Al modo en que se ha llevado a término el contenido de este precepto en la Comunidad Autónoma de Euskadi y en los Territorios Históricos de Álava, Gipuzkoa y Bizkaia creando sus propios órganos -lo que se llevó a cabo antes de la aprobación del TRLCSP- nos referimos seguida y separadamente.

Hay que advertir, por tanto, que en la Comunidad Autónoma de Euskadi se ha 212 optado por no seguir lo previsto en el apartado 3 del precepto transcrito cuando se 
establece que podrán las Comunidades Autónomas, previo el oportuno convenio, atribuir la competencia para la resolución de los recursos contractuales al estatal Tribunal Administrativo Central de Recursos Contractuales. Y asimismo, no resulta aquí de aplicación lo dispuesto en la Disposición Transitoria $2^{\text {a }}$ de la Ley 34/2010 -hoy contenida en la Transitoria $7^{\mathrm{a}}$ TRLCSP-sobre el régimen supletorio para las Comunidades Autónomas que no regulen esta cuestión.

\section{LOS ÓRGANOS COLEGIADOS-TRIBUNALES ADMINISTRATIVOS FORALES DE RECURSOS CONTRACTUALES DE LOS TERRITORIOS HISTÓRICOS DE ÁLAVA, GIPUZKOA Y BIZKAIA}

\subsection{Consideraciones generales}

Aprobada la reforma de la LCSP operada por la Ley 34/2010, de 5 de agosto, y con el marco competencial antes muy brevemente referido, los Territorios Históricos de Euskadi se apresuraron en crear sus propios órganos para la resolución de los recursos contractuales, al tiempo, y de un modo ciertamente coordinado dada la palmaria similitud de los órganos denominados en los Territorios de Gipuzkoa y Bizkaia "Tribunal Administrativo Foral de Recursos Contractuales" y en el de Álava "Órgano Administrativo Foral de Recursos Contractuales".

Se aprobó así en Gipuzkoa el Decreto Foral 24/2010, de 28 de septiembre, de creación y regulación del Tribunal Administrativo Foral de Recursos Contractuales ${ }^{11}$, en Álava el Decreto Foral 44/2010 de la misma fecha, de creación del Órgano Administrativo Foral de Recursos Contractuales ${ }^{12}$, y en Bizkaia el Decreto Foral 102/2010, de 29 de septiembre ${ }^{13}$.

Todas estas normas, además de coetáneas en el tiempo de aprobación, comparten mucho más que eso dada la apuntada y evidente similitud de los órganos que crean, que aunque en Álava tiene otra denominación, todos ellos son colegiados. Comparten incluso la exposición de motivos, que es idéntica en los tres Decretos Forales, indicando en todos ellos textualmente lo siguiente ${ }^{14}$ :

"La Directiva 2007/66/CE del Parlamento Europeo y del Consejo, de 11 de diciembre de 2007, por la que se modifican las Directivas 89/665/CEE y 92/13/CEE del Consejo en lo que respecta a la mejora de la eficacia de los procedimientos de recurso en materia de adjudicación de contratos públicos (DOUE de 20 de diciembre), ha establecido nuevas previsiones a fin de potenciar las garantías de transparencia y

11 Publicado en el Boletín Oficial de Gipuzkoa, n 203 de 22 de octubre de 2010, págs. 2 a 9.

12 Publicado en el Boletín Oficial del Territorio Histórico de Álava, n 115, de 8 de octubre de 2010, págs. 11119 a 11125 .

13 Publicado en el Boletín Oficial de Bizkaia, n 197, de 13 octubre de 2010, págs. 24537 a 24544.

14 El texto que reproducimos corresponde al Decreto Foral 24/2010, de Gipuzkoa. En los otros dos sólo cambian el nombre de la Diputación Foral a que se refieren. 
no discriminación y de dotar de recursos eficaces y rápidos contra decisiones adoptadas por poderes adjudicadores y entidades contratantes.

En concreto, y en relación con el órgano responsable de los procedimientos de recurso, el modelo consagrado por la Directiva 2007/66/CE permite optar entre un órgano jurisdiccional o un órgano administrativo que sea independiente del órgano de contratación. Así, la nueva redacción del artículo 2 de la Directiva 89/665/ CE establece en su apartado noveno las características de este último órgano y precisa que el nombramiento de quienes integren esta instancia independiente y la terminación de su mandato deberán sujetarse a las mismas condiciones aplicables a los jueces en lo relativo a la autoridad responsable de su nombramiento, la duración de su mandato y su revocabilidad. Como mínimo, añade la Directiva, el presidente o presidenta de esta instancia independiente deberá poseer las mismas cualificaciones jurídicas y profesionales que un juez. Concluye el repetido precepto señalando que esa instancia independiente adoptará sus decisiones previa realización de un procedimiento contradictorio y que tales decisiones tendrán, por los medios que estipule cada Estado miembro, efectos jurídicos vinculantes.

En cumplimiento de estas modificaciones, la Ley 34/2010, de 5 de agosto, de modificación de las Leyes 30/2007, de 30 de octubre, de Contratos del Sector Público, 31/2007, de 30 de octubre, sobre procedimientos de contratación en los sectores del agua, la energía, los transportes y los servicios postales, y 29/1998, de 13 de julio, reguladora de la Jurisdicción Contencioso-Administrativa, incorpora un nuevo libro, el VI, a la Ley de Contratos del Sector Público, dedicado en sus artículos 310 a 319 al recurso especial en materia de contratación; concretamente, el artículo 311 encomienda a un órgano administrativo independiente la resolución del recurso especial en materia de contratación que prevé, con carácter potestativo, el artículo 310. Dispone al respecto que la persona titular de dicho órgano independiente, o en el caso de que fuera colegiado, al menos su presidente o presidenta, ha de contar con una cualificación jurídica y profesional que garantice un adecuado conocimiento de las materias de que deba conocer. En cuanto al nombramiento de quienes integren esta instancia independiente, la terminación de su mandato y su revocabilidad, reitera el mandato de la Directiva de garantizar su independencia e inamovilidad.

De conformidad con la disposición adicional trigésimo tercera de la Ley 30/2007, de 30 de octubre, de Contratos del Sector Público, la Diputación Foral de Gipuzkoa ha de ajustar su contratación a las normas establecidas en dicha Ley para las administraciones públicas, lo cual implica la necesidad de crear en el seno de la Administración Foral, en ejercicio de su competencia de autoorganización, un órgano que atienda los cometidos señalados por la Unión Europea no sólo en lo referente a la mayor transparencia y no discriminación, sino, también, al reforzamiento de la seguridad jurídica en ese ámbito, siguiendo, a su vez, las pautas marcadas por la reciente reforma de la legislación sobre contratos públicos a la que se ha hecho mención.

A tal fin, el presente Decreto Foral crea el Tribunal Administrativo Foral de Recursos Contractuales, regulando a lo largo de los cuatro capítulos de los que consta, su adscripción orgánica, su composición y funciones con la vista puesta en garantizar su independencia funcional, la cualificación técnica y profesional de sus 
integrantes y su inamovilidad durante su mandato, así como los demás requerimientos establecidos en las normas antes citadas ....".

La constitución e inicio de actividades de estos Tribunales Administrativos no se hizo tampoco esperar, disponiéndose al efecto en los Decretos Forales mencionados (Disposición Final Primera), que la Diputación Foral designaría al Presidente y a los Vocales en el plazo de dos meses desde la entrada en vigor de los mismos, previéndose la constitución del órgano en el plazo de un mes desde la publicación en el correspondiente Boletín Oficial de la designación de sus miembros ${ }^{15}$.

\subsection{Naturaleza y ámbito competencial}

La naturaleza de los órganos referidos, de acuerdo con sus normas de creación, es la de "órgano especializado que actúa con plena independencia funcional en el ejercicio de sus competencias" (artículo 3 de los Decretos Forales), estando adscrito al Departamento correspondiente de la Diputación Foral' "sin integrarse en su estructura jerárquica" (artículo 1.2 de los Decretos Forales).

Subjetivamente, estos Tribunales son competentes para el "conocimiento y resolución de los recursos a los que se refiere el apartado 3 de este artículo, relativos a los contratos en los que sea parte la Diputación Foral de Gipuzkoa, su Administración Institucional y sus Sociedades Públicas Forales, y todos aquellos poderes adjudicadores que estén bajo su control en los términos del artículo 311.4 de la Ley 30/2007, de 30 de octubre, de Contratos del Sector Público"17, tal como reza el artículo 2.1 del Decreto Foral 24/2010, así como sus homónimos en los otros dos Territorios Históricos.

Como vemos, su competencia se extiende a toda la Administración, directa o indirecta, de la Diputación Foral, dejando de lado a las Juntas Generales, que atendiendo a lo preceptuado primero por la Disposición adicional trigésimo tercera LCSP y luego por el artículo 3.2.g) TRLCSP, habrán estas de contar con sus propios órganos para la resolución de recursos contractuales. Así se entiende el Acuerdo de la Mesa de las Juntas Generales de Bizkaia de 4 de octubre de 2011, por el que se determina el órgano competente para resolver los recursos especiales en materia de contratación en su ámbito de actuación.

15 Así, en Bizkaia se designaron al Presidente y vocales -titulares y suplentes- de su Tribunal Administrativo Foral de Recursos Contractuales por Decreto Foral 136/2010, de 23 de noviembre (Boletín Oficial de Bizkaia, $\mathrm{n}^{\circ} 233$, de 3 de diciembre de 2010, págs. 29434 y 29435).

En Álava por Acuerdo 764/2010, del Consejo de Diputados de 23 de diciembre de 2010 (Boletín Oficial del Territorio Histórico de Álava, $\mathrm{n}^{\circ}$ 137, de 1 de diciembre de 2010, pág. 13139).

Y en Gipuzkoa, por Acuerdo del Consejo de Diputados de 21 de diciembre de 2010 se designaron al Presidente y vocales -titulares- de su Tribunal (Boletín Oficial de Gipuzkoa, $\mathrm{n}^{\circ} 249$, de 30 de diciembre de 2010, pág. 17), quedando constituido el 28 de enero de 2011 (Boletín Oficial de Gipuzkoa, $n^{\circ} 24$, de 7 de febrero de 2011).

16 El Departamento de Presidencia y Administración Foral en Gipuzkoa, el de Relaciones Municipales y Administración Pública en Bizkaia, y el del Diputado General en Álava.

17 El contenido del mencionado artículo 311.4 LCSP está ahora en el artículo 41.5 TRLCSP. 
En el mencionado Acuerdo, sin renunciar las Juntas Generales de Bizkaia a, en el futuro, establecer su propio órgano, se proponía a la Diputación Foral la adopción de una Disposición Transitoria en el Decreto Foral 102/2010 que previera que, hasta que ello sucediera, resultara competente el Tribunal Administrativo Foral de Recursos Contractuales, lo que se introdujo con el Decreto Foral 167/2011, de 18 de octubre, que modificó el anterior en ese sentido ${ }^{18}$.

En el apartado 2 del mismo artículo 2 de los tres Decretos Forales se señala que el correspondiente Tribunal Administrativo "también será competente para conocer y resolver los recursos que se susciten con respecto a los contratos subvencionados sujetos a una regulación armonizada y contemplados en el artículo 17 de la Ley 30/2007, de 30 de octubre, que hayan recibido subvención por parte de las entidades a las que se refiere el apartado anterior y, en caso de concurrencia con otras administraciones públicas, cuando la cuantía de la subvención concedida por dicha entidades sea la de mayor importe y, en el caso de igualdad de importe, si quien recurre decide interponer el recurso ante el Tribunal Administrativo Foral de Recursos Contractuales, siempre que éste resulte competente conforme a las reglas anteriores". Previsión esta que no es más que reproducción del contenido del artículo 41.5 TRLCSP.

En cuanto al alcance objetivo de las competencias de estos Tribunales, se establece en el apartado 3 del artículo 2 de los Decretos Forales que "en concreto" conocerán:

“a) De la cuestión de nulidad prevista en los artículos 37 a 39 de la Ley 30/2007, de 30 de octubre ${ }^{19}$, y en los artículos 109 a 111 de la Ley 31/2007, de 30 de octubre, así como

b) del recurso o reclamación contra los actos mencionados en el artículo 310.2 de la Ley 30/2007, de 30 octubre $^{20}$, cuando se refieran a alguno de los contratos que se enumeran en el apartado 1 del mismo artículo o, en su caso, los mencionados en el artículo 101.1 a) de la Ley 31/2007, de 30 de octubre" ${ }^{21}$.

18 Se introdujo una nueva Disposición Transitoria Única Bis, del siguiente tenor literal:

“De conformidad con lo acordado por La Mesa de las Juntas Generales de Bizkaia en su sesión de 4 de octubre de 2011 y entre tanto dicha Institución no regule a este respecto, los recursos especiales del artículo 310 de la Ley de Contratos del Sector Público, que se interpongan en relación con los actos susceptibles de recurso contractual emanados de los poderes adjudicadores de las referidas Juntas Generales, serán conocidos y resueltos por el T.A.F.R.C regulado en el presente Decreto".

Tanto el Acuerdo de la Mesa de las Juntas Generales como el Decreto Foral 167/2011, se publicaron en el Boletín Oficial de Bizkaia, $n^{\circ} 203$, de 24 de octubre de 2011, págs. 23046 y 23047.

19 Preceptos contenidos ahora en los artículos 37 a 39 TRLCSP.

20 Este precepto es ahora el artículo 40.2 TRLCSP.

21 En el caso del Decreto Foral 24/2010, de Gipuzkoa, la sistemática del precepto es distinta aunque su alcance, como puede observarse, es el mismo de los dos anteriores transcrito en el texto. Este es el tenor de su artículo 2.3:

"En concreto, el Tribunal Administrativo Foral de Recursos Contractuales conocerá:

a) Del recurso especial en materia de contratación contra los actos mencionados en el artículo 310.2 de la Ley 30/2007, de 30 octubre, de Contratos del Sector Público, cuando se refieran a alguno de los contratos que se enumeran en el apartado 1 del mismo artículo. 


\subsection{Composición, designación y estatuto de sus miembros}

Llámense Tribunales u Órgano en Álava, los tres son órganos colegiados, y están compuestos por un Presidente y dos vocales, previéndose que "si el número de asuntos sometidos a su conocimiento así lo aconseja, se podrá incrementar el número de vocales que hayan de integrar el Tribunal, que siempre será impar" de acuerdo con el artículo 6.1 de los tres Decretos Forales, en los que se añade también la posibilidad de que, en determinadas circunstancias, pueda el Presidente proponer el nombramiento de un suplente: “... en los supuestos de ausencia, enfermedad u otra causa que sin ser motivo de cese imposibilite el cumplimento efectivo de las obligaciones de cualquiera de los miembros del Órgano durante un periodo superior a un mes y ello afectare de manera importante al trabajo del Órgano, su Presidente o Presidenta podrá solicitar al Diputado General que proponga al Consejo de Diputados la designación de un suplente que asuma las funciones del miembro ausente o imposibilitado hasta su reincorporación efectiva. El suplente debe reunir los requisitos establecidos para la designación de los vocales" (artículo 6.2).

La diferencia entre los tres Decretos Forales a este respecto está en el de Gipuzkoa, que añade al artículo 6.1 la previsión para el órgano de que "en su composición se garantizará la presencia equilibrada de mujeres y hombres con capacitación, competencia y preparación adecuada”.

La capacidad y competencia de los miembros del órgano tienen que ver con la necesidad de que el titular de estos órganos, o al menos su Presidente si es colegiado como es el caso en los Territorios Históricos, “ostente cualificaciones jurídicas y profesionales que garanticen un adecuado conocimiento de las materias que debe conocer", tal y como reza el artículo 41.3 TRLCSP.

Esta cuestión se solventa en los Territorios Históricos exigiendo que Presidente y vocales de estos órganos deban ser funcionarios de carrera de la Diputación Foral pertenecientes a un cuerpo o escala del Subgrupo A1, de acuerdo con la terminología que emplea la Ley 7/2007, de 12 de abril, del Estatuto Básico del Empleado Público ${ }^{22}$. A partir de ahí, se exige para el Presidente tener la licenciatura o el grado en Derecho y experiencia profesional, "preferentemente en el Ámbito del Derecho Administrativo relacionado con la contratación pública”, tal y como reza el artículo 8.1 de los tres Decretos Forales, en los que sólo varía la exigencia de años de esa experiencia: más de doce en Bizkaia y en Álava, más de diez en Gipuzkoa.

b) De la cuestión de nulidad regulada en los artículos 37 a 39 de la Ley 30/2007, de 30 de octubre, de Contratos del Sector Público.

c) De la reclamación en los procedimientos de adjudicación de los contratos y de la cuestión de nulidad, previstas en los artículos 101.1.a) y 109 a 111 de la Ley 31/2007, de 30 de octubre, sobre procedimientos de contratación en los sectores del agua, la energía, los transportes y los servicios postales".

22 Sobre esta cuestión, vid. por todos, Palomar Olmeda, A., Derecho de la Función Pública. Régimen jurídico de los funcionarios públicos, 9a ed., Dykinson, Madrid, 2011, págs. 200 a 205. 
Para ser vocal, la exigencia es menos rigurosa. Han de ser igualmente funcionarios de carrera de la Diputación Foral pertenecientes a cuerpos y escalas del Subgrupo A1, aunque a partir de ahí varían los requisitos de una Diputación Foral a otra. Así, en Álava se requiere además que estén "en servicio activo en dicha Administración y que hayan desempeñado su actividad profesional por tiempo superior a ocho años, preferentemente en el ámbito del Derecho Administrativo relacionado con la contratación pública" (artículo 10.1 Decreto Foral 44/2010), mientras que en Gipuzkoa es suficiente "que hayan desempeñado su actividad profesional por tiempo superior a cinco años, preferentemente en el ámbito del Derecho Administrativo" (artículo 10.1 Decreto Foral 24/2010), y en Bizkaia que ostenten "título de licenciado/a o de grado en Derecho que hayan desempeñado su actividad profesional por tiempo superior a ocho años, preferentemente en el ámbito del Derecho Administrativo relacionado con la contratación pública" (artículo 10.1 Decreto Foral 102/2010).

Esta desigual regulación no ofrece mayores problemas pues los requisitos exigidos, bien es cierto que en mayor o menor medida, consideramos que cubren las exigencias del básico artículo 41.3 TRLCSP.

Más allá de esta cuestión, nada se indica respecto de la retribución que hayan de percibir los miembros de estos órganos, ni sobre si han de tener dedicación exclusiva en los mismos, salvo en el caso del Decreto Foral 44/2010, de Álava, donde para el Presidente y los vocales expresamente se prevé que "el desempeño del cargo se podrá simultanear con el del puesto de trabajo al que está adscrito" (artículos 8.1 y 10.1 in fine). Circunstancia esta que entendemos que va ciertamente en detrimento de la imprescindible independencia del órgano.

En cuanto a la independencia funcional y no integración jerárquica, como notas de la requerida independencia de este tipo de órganos, también se han de predicar del estatuto jurídico de los miembros que lo integran, pues la mera adscripción del órgano a un Departamento "no altera su independencia, ya que no se integra en la estructura jerárquica de la Administración. Por ello, el órgano ejercita sus funciones con objetividad e imparcialidad, sin sujeción a vínculo jerárquico alguno ni instrucciones de ninguna clase de los órganos de las Administraciones Públicas afectadas"23, lo que se recalca en el artículo 5.1 de los respectivos Decretos Forales a que nos referimos:
"Los miembros del Tribunal ejercen su función con objetividad e imparciali- dad, sin sujeción a vínculo jerárquico alguno ni a instrucciones de ninguna clase de los órganos de la Diputación Foral”.

Aunque es la Diputación Foral correspondiente la que nombra a Presidente y vocales de estos Tribunales ${ }^{24}$, se establece que durante el tiempo de su mandato es-

23 Bernal Blay, M.A., "Aspectos orgánicos del recurso especial en materia de contratación pública en las Comunidades Autónomas”, op. cit., pág. 22.

24 Tanto al Presidente como a los vocales los designa el Consejo de Diputados, mediante Acuerdo Foral, a propuesta del Diputado General. A los nombramientos realizados nos hemos referimos en la nota 15 anterior. 
tos serán inamovibles, lo que es tanto como decir que no podrán ser removidos en el ejercicio de sus funciones salvo por la concurrencia de las causas tasadas que se establecen en el artículo 4.2 de los Decretos Forales: “a) Por expiración de su mandato; b) Por renuncia aceptada por el Consejo de Diputados; c) Por pérdida de los requisitos que son necesarios para su designación; d) Por incumplimiento grave de sus obligaciones; e) Por condena a pena privativa de libertad o de inhabilitación absoluta o especial para empleo o cargo público por razón de delito; f) Por incapacidad sobrevenida para el ejercicio de su función. La remoción por las causas previstas en las letras c), d), e) y f) se acordará por el Consejo de Diputados previo expediente instruido al efecto, con audiencia de la persona interesada".

En cuanto a la duración del mandato de los miembros de estos órganos, tanto para Presidente como para los vocales, es por un período de seis años, prorrogables por una sola vez (artículos 8.2 y 10.2 de los Decretos Forales), previéndose la renovación del órgano cada tres años "a razón de un miembro cada vez" (artículo 7) 25.

Se establece también la obligación de guardar secreto sobre los asuntos que traten (artículo 5.4 de los Decretos Forales), así como de inhibirse cuando concurran las causas de abstención y recusación de la Ley 30/1992, de 26 de noviembre, de Régimen jurídico de las Administraciones públicas y del procedimiento administrativo común (LRJPAC), incluyendo al respecto una previsión procedimental para resolver sobre ello el propio órgano, al disponerse (artículo 5.3) que:

"Cualquier miembro del Tribunal que sepa de la concurrencia de alguno de los supuestos previstos en el apartado anterior debe ponerlo en conocimiento del Tribunal, a fin de que éste decida, atendiendo a las circunstancias concretas de cada caso, si debe o no abstenerse del estudio y votación del asunto correspondiente. El Tribunal adopta el acuerdo que proceda en la misma sesión en que la cuestión se plantee, sin necesidad de ponencia previa. Los miembros afectados por posibles causas de abstención no pueden participar en el estudio, deliberación y votación sobre su apreciación que lleve a cabo el Tribunal, y quedan vinculados por el acuerdo que éste adopte".

\subsection{Normas de funcionamiento, procedimiento e impugnación de sus decisiones}

En cuanto órganos administrativos colegiados que son, a estos les resultarán de aplicación las previsiones de carácter básico que respecto de los mismos están conte-

25 El momento en que ello haya de comenzar a operar se fija en la Disposición Transitoria Única del Decreto Foral 44/2010 (Álava), en la Adicional Segunda del Decreto Foral 24/2010 (Gipuzkoa) y en la Transitoria Única del Decreto Foral 102/2010 (Bizkaia), todos ellos con igual tenor literal:

“1. La duración del mandato de quienes integren la primera composición del Tribunal será la que resulte de lo dispuesto en el apartado siguiente.

2. La primera renovación del Tribunal se efectuará a los tres años de la designación de sus miembros y recaerá en la o el vocal que se determine por medio de sorteo realizado al efecto. La segunda renovación tendrá lugar a los seis años de la designación y afectará al otro u otra vocal. La tercera renovación se llevará a cabo a los tres años de la segunda y será la del presidente o presidenta, que permanecerá en el cargo hasta entonces". 
nidas en el Capítulo II del Título II LRJPAC ${ }^{26}$, sin perjuicio de que en los tres Decretos Forales se contienen las funciones de Presidente (artículo $9^{27}$ ), vocales (artículo11 ${ }^{28}$ ) y Secretario (artículo 12).

En cuanto a la Secretaría de estos órganos, en los tres Territorios Históricos se opta por que esa función la asuma uno de los vocales, que será designado por acuerdo del propio órgano. Se trata por tanto de un Secretario con derecho a voto y que asumirá las siguientes facultades, en lo que coinciden los tres Decretos Forales considerados en su artículo 12.3: “a) Preparar y cursar el orden del día de las sesiones, así como la documentación necesaria relativa a los asuntos que hayan de tratarse en las mismas; b) Efectuar la convocatoria de las sesiones del Órgano por orden de la Presidencia, así como las citaciones pertinentes; c) Redactar y autorizar las actas de las sesiones; d) Expedir, por orden de la Presidencia y con su visto bue-

26 Recuérdese que la Sentencia del Tribunal Constitucional 50/1999, de 6 de abril, declaró el carácter no básico de algunos de los preceptos allí contenidos, en concreto los artículos 23.1 y 2, 24.1, 2 y 3, 25.2 y 3 y $27.2,3$ y 5 .

27 Son funciones del Presidente, atendiendo al precepto señalado, que es de igual tenor literal en los tres Decretos Forales, las siguientes:

“1. Son funciones de la Presidencia las previstas con carácter general para los órganos colegiados de las Administraciones Públicas y en particular:

a) La representación ordinaria del Órgano y la convocatoria de sesiones del mismo.

b) Programar sus actividades previa consulta a los/las vocales.

c) Convocar las sesiones y presidirlas, fijar el orden del día y proponer la inclusión de asuntos que no figuren en él cuando existan razones de urgencia que lo justifiquen.

d) Designar al ponente de cada asunto de acuerdo con los criterios aprobados por el propio Órgano, velando por una equilibrada asignación de la carga de trabajo entre sus miembros.

e) Visar las actas y certificaciones de los acuerdos del Órgano.

f) Cualesquiera otras que le atribuyan la normativa vigente o el Reglamento de Funcionamiento Interno.

2. Durante las sesiones, la persona que ostenta la presidencia, o quien le supla, ejerce las siguientes funciones:

a) Abrir y levantar las sesiones.

b) Dirigir y ordenar las deliberaciones

c) Dirimir con su voto los empates, a efectos de adoptar acuerdos.

3. Las facultades contempladas en el apartado 1, excepto la prevista en la letra a), son delegables en cualquiera de los vocales. En ausencia de delegación expresa, en casos de vacante, ausencia, enfermedad, abstención u otra causa legal, la Presidencia será suplida por el miembro presente de mayor antigüedad en el cargo, en caso de igualdad por el más antiguo como personal funcionario de los cuerpos o escalas que dan acceso a la condición de vocal y, si persistiera la igualdad, por el o la de mayor edad".

28 En los tres Decretos Forales, su artículo 11 establece que corresponde a los vocales del órgano:

“a) Recibir, con una antelación mínima de cuarenta y ocho horas, la convocatoria conteniendo el orden del día de las reuniones. La información sobre los temas que figuren en el orden del día estará a disposición de los miembros en igual plazo.

b) Redactar y presentar al Órgano las propuestas de resolución de los asuntos para los que hayan sido designados ponentes.

c) Asistir a las sesiones y participar en los debates.

d) Ejercer su derecho al voto y formular su voto particular, concurrente o discrepante con el parecer de la mayoría, así como expresar el sentido de su voto y los motivos que lo justifican.

e) Formular ruegos y preguntas

f) Obtener la información precisa para cumplir las funciones asignadas.

220 g) Cuantas otras funciones sean inherentes a su condición". 
no, certificaciones de actas, resoluciones y acuerdos; e) Recibir y llevar el registro de entrada y salida de las consultas, expediente y demás documentos que se dirijan al Órgano; f) Cualesquiera otras funciones inherentes al cargo de Secretaría de un órgano colegiado y las que le encomienden el Órgano o el Reglamento de funcionamiento interno", tal y como reza el precepto del Decreto Foral 44/2010, de Álava.

Interesa destacar que corresponde al Secretario la elaboración de un "proyecto de memoria anual de las actividades y de los extractos de doctrina emanada" del órgano, que será aprobada por este, así como la fijación de reglas para la suplencia del Presidente y del Secretario, considerando en primer lugar la antigüedad en el cargo, en segundo la antigüedad como personal funcionario del cuerpo o escala que dan acceso a la condición de vocal, y en último término la edad ${ }^{29}$.

Otro elemento que permite afirmar la autonomía del órgano es la previsión, contenida en los Decretos Forales de Álava y de Bizkaia, que otorgan al mismo la posibilidad elaborar un Reglamento Interno que se aprobará por Decreto Foral a propuesta del Diputado competente, el General en Álava y el de Relaciones Municipales y Administración Pública en Bizkaia. Esta previsión, sencillamente, no existe en el Decreto Foral 24/2010 de Gipuzkoa, aunque en los tres Decretos Forales se contienen prácticamente las mismas previsiones en cuanto al funcionamiento del órgano y normas procedimentales para el conocimiento de los recursos de su competencia, lo que seguidamente referimos.

Sin perjuicio de lo anterior, el Capítulo III de los tres Decretos Forales considerados se rubrica "funcionamiento", y allí se contienen preceptos relativos a la convocatoria de las sesiones (artículo 13) -que habrá de realizarse con entrega del orden del día y la documentación pertinente con al menos cuarenta y ocho horas de antelación-, quórum para la constitución y adopción de acuerdos (artículo 14)-válida constitución con Presidente y Secretario, adopción de acuerdos por mayoría de votos, siendo de calidad el del Presidente, sin que quepa la abstención salvo por las circunstancias del artículo 28 LRJPAC-, votos particulares (artículo 15) y el contenido y aprobación del acta (artículo 16).

Del procedimiento para la tramitación y resolución de los recursos para los que estos órganos son competentes se ocupa el Capítulo IV de los Decretos Forales con el mismo contenido dispositivo, que se circunscribe a mencionar las normas correspondientes de la legislación básica de contratos, a hacer una llamada a la supletoriedad de acuerdo con la anterior a la LRJPAC, así como a declarar que las resoluciones de estos órganos agotan la vía administrativa y contra los mismos sólo podrá interponerse recurso contencioso-administrativo. Disposiciones estas que tienen en los tres Decretos Forales el siguiente tenor literal:

29 Más antigüedad y edad para suplir al Presidente, menos para hacer lo propio con el Secretario. Vid. los artículos 9.3 y 12.2 de los tres Decretos Forales considerados. 
“Artículo 17. Iniciación, tramitación y resolución de los recursos.

La interposición, tramitación y resolución de los recursos contractuales se realiza con arreglo al procedimiento establecido al efecto en la normativa sobre contratación administrativa y, en concreto, a lo dispuesto en:

a) Los artículos 310 a 319 de la Ley 30/2007, de 30 de octubre, de Contratos del Sector Público ${ }^{30}$, con las especialidades señaladas en el artículo $39^{31}$, cuando se trate de una cuestión de nulidad.

b) Los artículos 103 a 108 de la Ley 31/2007, de 30 de octubre, sobre procedimientos de contratación en los sectores del agua, la energía, los transportes y los servicios postales, con las especialidades señaladas en el artículo 111, cuando se trate de una cuestión de nulidad.

Artículo 18. Normas supletorias.

En lo no previsto en las normas citadas en el artículo anterior y, de conformidad con lo dispuesto en los artículos 316 de la Ley 30/200732 y 105 de la Ley 31/2007, será de aplicación supletoria la Ley 30/1992, de 26 de noviembre.

Artículo 19. Impugnación de las resoluciones y actos del Órgano Administrativo Foral de Recursos contractuales.

En virtud de lo establecido en la normativa vigente en materia de contratación administrativa y en la Ley 29/1998, de 13 de julio, Reguladora de la Jurisdicción Contencioso-Administrativa, las resoluciones y los actos dictados por el Órgano Administrativo Foral de Recursos Contractuales no serán objeto de recurso en vía administrativa y contra los mismos sólo podrá interponerse recurso contencioso-administrativo".

Finalmente, en cuanto a los medios de que hayan de disponer estos órganos, sólo en el Decreto Foral 24/2010, de Gipuzkoa, se contiene una previsión al respecto. Su Disposición Adicional 1", cuando establece que "el Tribunal Administrativo Foral de Recursos Contractuales contará, para su funcionamiento, con el apoyo técnico y administrativo de la Dirección General de Régimen Jurídico".

\section{EL ÓRGANO ADMINISTRATIVO DE RECURSOS CONTRACTUALES DE LA COMUNIDAD AUTÓNOMA DE EUSKADI}

\subsection{Creación, naturaleza y composición unipersonal “inicial”}

Señalado todo lo anterior, la creación del Órgano Administrativo de Recursos Contractuales de la Comunidad Autónoma de Euskadi se llevó a cabo, con posteriori-

30 Artículo 40 a 49 TRLCSP.

22231 Artículo 39 TRLCSP. 
dad a los Territorios Históricos, con la aprobación de la Ley 5/2010, de 23 de diciembre, por la que se aprueban los Presupuestos Generales de la Comunidad Autónoma de Euskadi para el ejercicio 201133, en cuya Disposición Adicional Octava "se crea el Órgano Administrativo de Recursos Contractuales de la Comunidad Autónoma de Euskadi" (apartado 1), disponiendo además que "su naturaleza es la de un órgano administrativo especializado que actúa con plena independencia funcional en el ejercicio de sus competencias" (apartado 1, último párrafo).

La opción aquí seguida es la de un órgano unipersonal, a diferencia de lo que sucede en los Territorios Históricos, aunque esa determinación legal aparece como provisional ya que se prevé -como luego veremos- su transformación en órgano colegiado si se dieran determinadas circunstancias y, principalmente, porque teniendo eso en cuenta, el apartado 7 de la señala Disposición Adicional establece que "el Órgano Administrativo de Recursos Contractuales de la Comunidad Autónoma de Euskadi se crea inicialmente con el carácter de unipersonal".

Que el órgano sea personal o colegiado recordemos que una opción del legislador autonómico expresamente habilitada por el precepto ahora contenido en el artículo 41 TRLCSP, antes transcrito. Y que la Comunidad de Euskadi se haya decantado por un órgano unipersonal consideramos que es una decisión que hay que enmarcar en las políticas de austeridad en el gasto público que se vienen impulsando desde el Gobierno Vasco, pues en la Memoria de los Presupuestos Generales de la Comunidad Autónoma para 2011, tras mencionar el contenido de la señalada Disposición Adicional Octava, se explica lo siguiente:

\begin{abstract}
"Para dar cumplimiento a este mandato, y teniendo en cuenta lo novedoso de la figura, el criterio de austeridad presente en el gasto público y la necesidad de racionalización de los recursos disponibles, se opta por la creación de un órgano unipersonal cuya competencia abarca además de los actos recurribles emanados de poderes adjudicadores de la Administración de la Comunidad Autónoma del País vasco, los emanados de poderes adjudicadores de las Administraciones locales integradas en el territorio de la CAE cuyos municipios cuenten con una población, igual o inferior a 50.000 habitantes" 34 .
\end{abstract}

Órgano colegiado, por tanto, de carácter unipersonal, tal y como permite el ya visto apartado 4 del artículo 41 TRLCSP. Además, de acuerdo con la Disposición Adicional Octava de su Ley de creación, este órgano "ejerce sus funciones con plena independencia y se adscribe, sin integrarse en la estructura jerárquica de la Administración, al departamento competente en materia de contratación pública" (apartado 4), y "ejercitará su función con objetividad e imparcialidad, sin sujeción a vínculo jerárquico alguno ni instrucciones de ninguna clase de los órganos de las administraciones públicas afectadas" (apartado 6).

33 Publicada en el Boletín Oficial del País Vasco, $\mathrm{n}^{\circ} 250$, de 30 de diciembre de 2010, y en el BOE, $\mathrm{n}^{\circ}$ 36 de 11 de febrero de 2011, págs. 14600 a 14703.

34 Presupuestos Generales de la Comunidad Autónoma de Euskadi 2011, Memoria Explicativa-Tomo 1, Departamento de Economía y Hacienda-Gobierno Vasco, Vitoria-Gasteiz, 2011, pág. 85. 
El Departamento del Gobierno Vasco al que se adscribe es el de Justicia y Administración Pública35, teniendo su sede donde sus órganos centrales, "si bien el Gobierno Vasco podrá acordar el traslado a otras dependencias cuando las necesidades que demande el correcto funcionamiento del órgano así lo aconsejen" (apartado 5). Asimismo y en consecuencia, se establece que "la Administración de la Comunidad Autónoma de Euskadi garantizará la disponibilidad de los medios personales y materiales que el órgano administrativo regulado en esta disposición precise para su adecuado funcionamiento" (apartado 12).

En cuanto al inicio de las actividades del Órgano Administrativo de Recursos Contractuales de la Comunidad Autónoma de Euskadi, la Disposición Adicional Octava de la Ley 5/2010 la fija "al día siguiente de la publicación del nombramiento de su titular" (apartado 13), lo que tuvo lugar el 4 de junio de 2011, al publicarse en el Boletín Oficial del País Vasco n 105 de 3 de junio de 2011 el Decreto 103/2011, de 31 de mayo, "por el que se nombra el Órgano Administrativo de Recursos Contractuales de la Comunidad Autónoma de Euskadi", donde se nombro también al suplente ${ }^{36}$.

Disposición esta que fue objeto de una corrección de errores unos días después y que afectó incluso al título del Decreto señalado, que en realidad es "por el que se nombra al titular" del mencionado órgano, como resulta obvio ${ }^{37}$.

\subsection{Competencias, ámbito de actuación y procedimiento}

El ámbito sujetivo en el que el Órgano Administrativo de Recursos Contractuales de la Comunidad Autónoma de Euskadi ejercerá sus competencias abarca, con arreglo al apartado 2 de la Disposición Adicional 8 a de la Ley 5/2010, a "la Administración de la Comunidad Autónoma de Euskadi y las administraciones locales integradas en el territorio de dicha Comunidad".

Asimismo, y de acuerdo con lo dispuesto en el artículo 41.4 TRLCSP, cuando establece que respecto de las Corporaciones Locales la competencia para resolver los recursos en materia de contratación "será establecida por las normas de las Comunidades Autónomas cuando éstas tengan atribuida competencia normativa y de ejecución en materia de régimen local y de contratación", la misma Disposición de la Ley

35 Este es el Departamento al que corresponden las funciones en materia de "contratación”, con arreglo al artículo 9.1.h) del Decreto 4/2009, de 8 de mayo, del Lehendakari, de creación, supresión y modificación de los Departamentos de la Administración de la Comunidad Autónoma del País Vasco y de determinación de funciones y áreas de actuación de los mismos (Boletín Oficial del País Vasco, n 86, de 9 de mayo de 2009).

36 Hasta esa fecha, habrá que estar a la Disposición Transitoria $1^{\text {a }}$ de la Ley 5/2010, que rubricada “Órgano Administrativo de Recursos Contractuales de la Comunidad Autónoma de Euskadi” establece:

"Los recursos especiales interpuestos con anterioridad a la publicación del nombramiento del titular y los suplentes del Órgano Administrativo de Recursos Contractuales de la Comunidad Autónoma de Euskadi continuarán tramitándose, hasta su finalización, por el órgano que estuviera conociendo de los mismos".

37 Publicada en el Boletín Oficial del País Vasco, $\mathrm{n}^{\circ}$ 115, de 17 de junio de 2011. 
5/2010 habilita a los municipios vascos de más de 50.000 habitantes para dotarse de su propio órgano de resolución de recursos:

“Los municipios de más de 50.000 habitantes integrados en el territorio de la Comunidad Autónoma de Euskadi podrán crear su propio órgano competente para la resolución de los recursos de su ámbito local y sector público respectivo, con arreglo a los requisitos establecidos en el apartado 2 del artículo 311 de la Ley de Contratos del Sector Público, en la redacción dada por la Ley 34/2010, de 5 de agosto ${ }^{38 "}$.

Esta habilitación, así como el hecho de que ya existan órganos para la resolución de recursos contractuales en las tres Diputaciones Forales, es una cuestión que hoy en día hay que abordar a la luz de la iniciativa del Gobierno Vasco de constituir el 22 de noviembre de 2011, en el Parlamento Vasco, la "Comisión de estudio sobre duplicidades e ineficiencias existentes en el entramado institucional vasco", en la que elaborado un estudio por parte de las Consultoras Deloitte y Everis ${ }^{39}$, inició sus sesiones de trabajo el 11 de enero de 2012, marco en el cual los grandes municipios vascos de Bilbao, Vitoria y San Sebastián han afirmado su intención de no dotarse de ese órgano ${ }^{40}$.

Desde luego, que en el ámbito de Euskadi se cuente con cuatro órganos para la resolución de recursos contractuales, es una cuestión que se incluye dentro de un planteamiento más amplio que afecta a todo su entramado institucional, pero que en este ámbito no puede dejar de apuntarse. Por el momento, se ha iniciado una reflexión.

Continuando con el ámbito competencial del Órgano Administrativo de Recursos Contractuales de la Comunidad Autónoma de Euskadi, y sin perjuicio de que el Parlamento Vasco constituya el suyo propio -lo que por lo señalado es poco probable-, la señalada Disposición Adicional $8^{a} .2$ de la Ley 5/2010 otorgas tales competencias a aquél hasta que ello suceda:

\begin{abstract}
“Así mismo, y en tanto no se regule por el Parlamento Vasco y los organismos creados por esta institución el órgano competente para resolver los recursos especiales en materia de contratación dentro de su respectivo ámbito, tal y como prevé el artículo 311.2 de la Ley de Contratos del Sector Público ${ }^{41}$, el Órgano Administrativo de Recursos Contractuales de la Comunidad Autónoma de Euskadi ejercerá sus funciones respecto de los actos susceptibles de recurso contractual emanados de sus poderes adjudicadores".
\end{abstract}

En lo que se refiere a la competencia material del Órgano Administrativo de Recursos Contractuales de la Comunidad Autónoma de Euskadi, el apartado 3 de la Disposición Adicional $8^{a}$ de la Ley 5/2001 establece que alcanzará a los siguientes actos:

38 Artículo 41.3 TRLCSP.

39 Se ha publicado una nota de prensa sobre ese informe en: http://www.irekia.euskadi.net/ assets/a_documents/1494/Informe_de_duplicidades.pdf?1317756923 (3.4.2012).

40 EL PAís, Edición País Vasco, 27 de febrero de 2012.

41 Artículo 41.3 TRLCSP. 
“a) Resolver los recursos especiales en materia de contratación que se interpongan contra los actos relacionados en el apartado 2 del artículo 310 de la Ley 30/2007, de 30 de octubre, de Contratos del Sector Público, en la redacción dada por la Ley $34 / 2010$, de 5 de agosto, cuando se refieran a los tipos de contratos que se citan en el apartado 1 del mismo precepto ${ }^{42}$.

b) Decidir sobre la adopción de medidas provisionales que, con anterioridad a la interposición del recurso especial en materia de contratación, se hayan solicitado por los legitimados para interponer dicho recurso.

c) Resolver las cuestiones de nulidad basadas en los supuestos especiales de nulidad contractual recogidos en el artículo 37.1 de la Ley de Contratos del Sector Público, así mismo en la redacción dada por la Ley 34/2010, de 5 de agosto ${ }^{43}$.

d) Resolver las reclamaciones en los procedimientos de adjudicación de los contratos y de la cuestión de nulidad, previstas en los artículos 101 y 109 a 111 de la Ley 31/2007, de 30 de octubre, sobre procedimientos de contratación en los sectores del agua, la energía, los transportes y los servicios postales, en la redacción dada por la Ley 34/2010, de 5 de agosto".

Como vemos, empleándose una sistemática distinta a la seguida en los Decretos Forales que regulan los órganos para la resolución de recursos contractuales, ya vistos, el alcance objetivo de su competencia es prácticamente el mismo. Simplemente advertir que la referencia expresa en relación con las medidas provisionales está ya regulada en el artículo 43 TRLCSP cuya rúbrica es "solicitud de medidas provisionales" -antes el 313 LCSP con la redacción de la Ley 34/2010- y en el artículo 103 de la Ley 31/2007, preceptos que se insertan en los relativos a la tramitación del recurso más que en la competencia del órgano, pues ésta va de suyo.

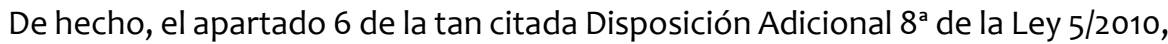
establece que "la interposición, tramitación y resolución de los recursos contractuales se realizará con arreglo al procedimiento establecido al efecto en la normativa sobre contratación administrativa, y en concreto a lo dispuesto en:

a) Los artículos 310 a 319 de Ley 30/2007, de 30 de octubre, de Contratos del Sector Público ${ }^{44}$, con las especialidades señaladas en el artículo $39^{45}$, cuando se trata de una cuestión de nulidad.

b) Los artículos 101 a 108 de la Ley 31/2007, de 30 de octubre, sobre procedimientos de contratación en los sectores del agua, la energía, los transportes y los servicios postales, con las especialidades señaladas en el artículo 111, cuando se trate de una cuestión de nulidad".

42 Artículo 40.2 TRLCSP.

43 Artículo 37.1 TRLCSP.

44 Artículos 40 a 49 TRLCSP.

45 Artículo 39 TRLCSP. 
Se afirma igualmente la aplicación supletoria de la LRJPAC y, permitiendo el artículo 41.2 TRLCSP que las Comunidades Autónomas puedan prever un recurso administrativo previo al previsto la especial en materia de contratación, en el País Vasco se ha decidido no hacerlo, estableciéndose en la mencionada Disposición de modo expreso que "contra los actos enumerados en el artículo 310.2 de la Ley de Contratos del Sector Público ${ }^{46}$ no podrá interponerse recurso administrativo previo al contemplado en dicho artículo".

\subsection{La garantía de la independencia. El estatuto y cualificación de su titular}

Ya hemos visto como siendo la principal característica de este órgano la independencia de su titular, la misma es perfectamente predicable del unipersonal que se crea en el País Vasco. El apartado 9 de la Disposición Adicional $8^{a}$ de la Ley 5/2010 se refiere al "estatuto personal del órgano", lo que es entendible para su titular, y que se concreta en las siguientes notas:

“a) Su designación se realizará por el Gobierno Vasco mediante decreto acordado en Consejo de Gobierno a propuesta conjunta y motivada de los titulares de los departamentos de Economía y Hacienda y de Justicia y Administración Pública. El decreto de nombramiento se publicará en el Boletín Oficial del País Vasco.

b) Es inamovible y su mandato tiene una duración de seis años contados a partir del mismo día de su toma de posesión, que se efectuará una vez publicado su nombramiento. El titular del órgano podrá volver a ser nombrado por periodos sucesivos de la misma duración.

c) El nombramiento para ostentar la titularidad del órgano da lugar a la declaración de la situación administrativa de servicios especiales en el cuerpo de origen.

d) El titular o la titular será remunerado mediante una única retribución y por un solo concepto. La cuantía de su retribución para el ejercicio 2011 será de 67.083,41 euros. Su devengo y actualización, así como el resarcimiento de cuantos gastos se vea obligado a realizar por razón del servicio o por traslado de residencia, se realizan en las mismas condiciones que rigen para los altos cargos de la Administración".

Ya vimos que se designó al titular del órgano y a su suplente con el Decreto 103/2011, de 31 de mayo.

En cuanto a fijar en una norma con rango de Ley sus retribuciones -lo que es una garantía de independencia- hay que destacar que la única Comunidad Autónoma que lo ha hecho es la de Euskadi47. Cuantías las mencionadas, por cierto, que no se han incrementado para el ejercicio 2012, de acuerdo con el artículo 19.12 de la Ley 6/2011,

46 Artículo 40.2 TRLCSP.

47 Como constata Bernal Blay, M.A., “Aspectos orgánicos del recurso especial en materia de contratación pública en las Comunidades Autónomas”, op. cit., pág. 23. 
de 23 de diciembre, por la que se aprueban los Presupuestos Generales de la Comunidad Autónoma de Euskadi para ese ejercicio ${ }^{48}$.

Garantía de independencia es también la inamovilidad y la duración de su mandato, mucho mayor que la duración de una legislatura: seis años, lo que no sucede igual en el ámbito del Estado ni en otras Comunidades Autónomas, con períodos inferiores ${ }^{49}$, pudiendo ser designado para períodos sucesivos de la misma duración.

La señalada inmovilidad está en directa relación con las causas tasadas por las que puede ser removido de su puesto, y que se concretan en el apartado 10 de la Disposición Adicional $8^{\text {a }}$ de la Ley 5/2010, en las siguientes:

“a) Fallecimiento.

b) Expiración de su mandato.

c) Renuncia formalizada por escrito y aceptada por el Gobierno Vasco.

d) Pérdida de los requisitos que son necesarios para su designación.

f) Condena a pena privativa de libertad o de inhabilitación absoluta o especial para empleo o cargo público por razón de delito.

g) Incapacidad sobrevenida para el ejercicio de su función".

Ni que decir tiene que salvo para los casos de fallecimiento, expiración del mandato y renuncia, será preciso un expediente contradictorio previo con audiencia del interesado, lo que de acuerdo con la señalada Disposición se acordará por el Gobierno Vasco. Asimismo, el cese o remoción en todo caso habrá de formalizarse mediante Decreto y publicarse en el Boletín Oficial del País Vasco.

Otro aspecto que garantiza o, si se quiere, refuerza la independencia del titular del órgano, y más si es unipersonal, es su dedicación exclusiva. Esta es palmaria dada la retribución que se fija y que, siendo funcionario -como inmediatamente veremos que se exige- su nombramiento dé lugar a la situación de servicios especiales ${ }^{50}$.

Respecto de la especialización y competencia profesional del titular del órgano, el apartado 8 de la Disposición Adicional $8^{\text {a }}$ de la Ley 5/2010 exige que sea funcionario de carrera con más de quince años de experiencia profesional y que ésta esté relacionada con la contratación pública:

48 Publicada en el Boletín Oficial del País Vasco $n^{\circ} 247$ de 30 de diciembre de 2011, y en el BOE $n^{\circ} 19$, de 23 de enero de 2012, págs. 5400 a 5525.

49 Bernal Blay, M.A., "Aspectos orgánicos del recurso especial en materia de contratación pública en las Comunidades Autónomas”, op. cit., págs. 22 y 23.

50 Ya vimos que en el caso de Álava, los miembros del colegiado Órgano Administrativo Foral de Recursos pueden simultanear el desempeño de su cargo con otros puestos de trabajo en la Diputación Foral. 
“El órgano unipersonal se nombrará de entre quienes, teniendo la licenciatura o el doctorado en Derecho, cuenten con acreditada competencia profesional en las materias que ha de conocer el órgano y, además, sean funcionarios o funcionarias de carrera que hayan desempeñado su actividad profesional por tiempo superior a quince años, en cualquiera de las administraciones públicas de la Comunidad Autónoma de Euskadi, preferentemente en el ámbito del Derecho Administrativo relacionado directamente con la contratación pública".

Como podemos observar, y esto es una peculiaridad, se exige ser funcionario de carrera de cualquiera de las Administraciones públicas de Euskadi, con lo que este cargo queda abierto a los de la propia Comunidad Autónoma, a los de las Corporaciones Locales y, desde luego, a los de las tres Diputaciones Forales.

Tratándose de un órgano unipersonal, queda hacer referencia a la situación en que queda este en los casos de vacante, ausencia o enfermedad. A ello se refiere el apartado 11 de la misma Disposición Adicional $8^{\text {a }}$ citada, en los siguientes términos:

"Dado el carácter de unipersonal con que se crea inicialmente este órgano y a fin de dar continuidad a las competencias asignadas al mismo, el Gobierno Vasco, a propuesta conjunta de los titulares de los departamentos de Economía y Hacienda y de Justicia y Administración Pública, designará en el mismo acto del nombramiento del titular o la titular del órgano a la persona o personas que, reuniendo los mismos requisitos exigidos para el titular del órgano, estén llamadas a sustituirle con carácter temporal en los supuestos de vacante, ausencia o enfermedad, de conformidad con lo dispuesto en el artículo 17 de la Ley 30/1992, de 26 de noviembre, de régimen Jurídico de las Administraciones Públicas y del Procedimiento Administrativo Común ${ }^{51}$.

Cuando por darse alguna de las circunstancias señaladas la persona llamada a sustituir al titular del órgano deba ejercer las funciones asignadas a éste, el sustituto ejercerá tales funciones en las mismas condiciones exigidas al titular del órgano.

Durante el tiempo en el que efectivamente ejerza como Órgano Administrativo de Recursos Contractuales de la Comunidad Autónoma de Euskadi, pasará a la situación administrativa de servicios especiales en el cuerpo de origen y percibirá las retribuciones que correspondan conforme a lo establecido en el apartado 9.d de esta disposición adicional”.

Queda así claro que en esta situación no se compromete ni la independencia ni la especialización del órgano, pues el suplente ha de reunir los mismos requisitos

51 Recordemos que este precepto establece que:

“1. Los titulares de los órganos administrativos podrán ser suplidos temporalmente en los supuestos de vacante, ausencia o enfermedad por quien designe el órgano competente para el nombramiento de aquéllos. Si no se designa suplente, la competencia del órgano administrativo se ejercerá por quien designe el órgano administrativo inmediato de quien dependa.

2. La suplencia no implicará alteración de la competencia".

El texto que hemos señalado en cursiva fue declarado inconstitucional por contrario al orden de distribución de competencias por la Sentencia del Tribunal Constitucional 50/1999, de 6 de abril de 1999. 
que su titular, fue en efecto nombrado en el mismo Decreto 103/2011, de 31 de mayo, y la dedicación exclusiva se garantiza con su paso a la situación de servicios especiales, con las mismas retribuciones -durante el período que dure la suplencia- que el titular.

Finalmente, en cuanto a los medios personales y materiales precisos para el correcto funcionamiento del órgano, nada se especifica en la norma de creación del mismo, salvo el otorgamiento al Gobierno Vasco de la correspondiente autorización para adoptar "cuantas disposiciones reglamentarias sean precisas o convenientes para el correcto funcionamiento del órgano que se crea" (Disposición Adicional $8^{a}$ Ley 5/2010).

Sobre esta cuestión ha sido preguntado el Gobierno Vasco en el Parlamento, en concreto respecto de los medios personales con los que se ha dotado al Órgano, respondiéndose el 5 de septiembre de 2011 que -además de la referencia a su titular“inicialmente y hasta conocer el volumen de asuntos a tratar, se le está dotando de un funcionario licenciado en derecho con experiencia en contratación de más de 5 años y personal administrativo necesario". Y en cuanto a los medios materiales, la respuesta fue que "además de tener asignado un especio físico adecuado, está dotado de infraestructura y medios informáticos amplios y suficientes" ${ }^{2}$.

La dotación económica prevista en los Presupuestos Generales de 2012 de la Comunidad Autónoma de Euskadi para este Órgano asciende a 209.400 euros, de los que 199.400 son para gastos de personal, y 10.000 para gastos de funcionamiento.

\subsection{Condicionantes para la futura creación de un órgano colegiado.}

Como se ha señalado, la decisión de crear un órgano para la resolución de los recursos contractuales en Euskadi se adoptó con un carácter aparentemente provisional ya que se señalaba en su Ley de creación que "inicialmente" tendría carácter unipersonal, siendo la regulación vista hasta el momento la correspondiente a un órgano de tales características.

Tal afirmación es consecuente con lo dispuesto en el apartado 14 de la Disposición Adicional $8^{a}$ de la Ley 5/2010, que autorizando en términos generales al Gobierno Vasco para el desarrollo reglamentario, hace especial mención al caso en que se constituya un órgano colegiado transformado así el unipersonal ya existente, que cambiaría su denominación a la de Tribunal Administrativo de Recursos Contractuales de la Comunidad Autónoma de Euskadi. Se da aquí por tanto una deslegalización de la de-

52 Así se expresa en la Contestación a la pregunta para su respuesta escrita formulada por Dña. Ana Otadiu Biteri, del Grupo Nacionalistas Vascos, relativa a los medios personales y materiales con que se ha dotado al Órgano Administrativo de Recursos Contractuales de la Comunidad Autónoma de Euskadi. 
cisión, que competerá al Gobierno Vasco, aunque introduciendo una serie de cautelas tanto de carácter formal como de carácter material.

Formalmente, tal decisión se habrá de adoptar por Decreto, debiendo dar cuenta del mismo al Parlamento Vasco. Y ello con un presupuesto de hecho previo, cual es que "el volumen y la especificidad de los asuntos competencia del Órgano Administrativo de Recursos Contractuales de la Comunidad Autónoma de Euskadi así lo requieran o aconsejen".

Materialmente, la mencionada Disposición de la Ley 5/2010 condiciona el contenido del futuro Decreto regulador del denominado Tribunal, que deberá ajustarse a las siguientes previsiones:

“a) El tribunal estará compuesto por un presidente o presidenta y un mínimo de dos vocales, pudiendo incrementarse el número de vocales que hayan de integrar el tribunal cuando el volumen de asuntos sometidos a su conocimiento lo requiera o aconseje.

b) En tal supuesto, el titular o la titular del Órgano Administrativo de Recursos Contractuales pasará a formar parte del tribunal, en calidad de presidente y por el tiempo que le reste de mandato, sin perjuicio de su eventual renovación.

c) En el procedimiento de nombramiento de los miembros del órgano colegiado se ha de garantizar la presencia en el mismo de un vocal, como mínimo, designado a propuesta de la Asociación de Municipios Vascos-Eudel.

d) El estatuto personal del presidente o presidenta y los vocales o las vocales del tribunal, así como los requisitos de nombramiento, duración y cese o remoción serán los establecidos en los apartados 8, 9 y 10 de esta disposición adicional para el órgano unipersonal creado.

e) El decreto en virtud del cual tenga lugar la transformación del carácter unipersonal del Órgano Administrativo de Recursos Contractuales en tribunal deberá contener el reglamento de organización y funcionamiento del órgano colegiado".

Condicionantes, los señalados, que dan continuidad al órgano pese a su posible cambio de naturaleza, al integrar al titular del órgano unipersonal como Presidente y hasta que termine su mandato, manteniendo igualmente el estatuto personal para todos sus miembros -incluido el régimen retributivo ${ }^{53}$ - y fijando inicialmente el número de tres miembros, debiendo ser uno de ellos a propuesta de la Asociación de Municipios Vascos. Además, es loable que se previa la aprobación -con carácter simultáneo a la transformación- de un reglamento de organización y funcionamiento.

53 Destacar que a estos efectos no se distingue entre el Presidente y los Vocales, lo que puede plantear algún problema ya que por la remisión a los preceptos donde ello se regula hará difícil que las retribuciones de unos y otros no sean las mismas, como sería razonable dadas las mayores facultades y responsabilidades de los Presidentes de órganos colegiados. En cuanto al Secretario, como nada se predispone, habrá que estar a lo que se explicite en el futuro reglamento de funcionamiento. 


\section{BIBLIOGRAFÍA CITADA}

Bernal Blay, M.A., “Aspectos orgánicos del recurso especial en materia de contratación pública en las Comunidades Autónomas", Cuadernos de Derecho Local, n² 6 (2011).

Canales Gil. A. y Huerta Barajas, J.A., La contratación del sector público tras las reformas de 2010, Reus, Madrid, 2010.

Castells Arteche, J.M., "El hecho diferencial vasco", Revista Vasca de Administración Pública, n 47-II (1997).

Cortés Moreno, A., “La adaptación de la Ley 30/2007, de 30 de octubre, de Contratos del Sector Público a la Directiva 2007/66/CE realizada por la Ley 34/2010, de 5 de agosto", El Consultor de los Ayuntamientos y de los Juzgados, $\mathrm{n}^{\circ} 24$, Sección Actualidad, Quincena del 30 diciembre 2010 al 14 enero 2011.

Entrena Ruiz, D., “Disposición Adicional Trigésimo Tercera”, Comentarios a la Ley de Contratos del Sector Público (Parejo, L. y Palomar, A., Dirs.), Tomo IV, Bosch, Barcelona, 2009.

Fernández Rodríguez, T.R., Los derechos históricos de los territorios forales, CEC-Civitas, Madrid, 1985.

Gallego Córcoles, I., “Comentario a la Ley 34/2010, de 5 de agosto, de modificación de las Leyes 30/2007, de 30 de octubre, de Contratos del Sector Público, 31/2007, de 30 de octubre, sobre procedimientos de contratación en los sectores del agua, la energía, los transportes y los servicios postales, y 29/1998, de 13 de julio, reguladora de la Jurisdicción Contencioso-Administrativa para adaptación a la normativa comunitaria de las dos primeras", Contratación Del Sector Público Local, $2^{\text {a }}$ ed., La Ley-El Consultor, Madrid, 2010.

Gimeno Feliu, J.M., “El nuevo sistema de recursos en materia de contratos públicos”, Observatorio de Contratos Públicos 2010, Aranzadi Civitas, Navarra, 2010.

Jiménez Asensio, R., “El sistema de fuentes del Derecho de la Comunidad Autónoma del País Vasco como 'ordenamiento asimétrico"”, Revista Vasca de Administración Pública, $\mathrm{n}^{\circ}$ 47-II (1997).

Larrazabal Basañez, S., “¿26 años no es nada... ? Luces y sombras en la distribución de competencias entre las instituciones Comunes de la Comunidad Autónoma del País Vasco y las de sus Territorios Históricos", Revista Vasca de Administración Pública, $\mathrm{n}^{\circ} 87-88$ (2010).

Moreno Molina, J.A., "La Ley 34/2010 y al adaptación en España del derecho de la Unión Europea en materia de recursos en los procedimientos de adjudicación de contratos públicos", Revista General de Derecho Administrativo, n² 25 (2010).

- "La falta de adecuación de la Ley española de Contratos del Sector Público al Derecho Comunitario Europeo", Monografía de la Revista Aragonesa de Administración Pública (Agua, territorio, cambio climático y Derecho Administrativo), $\mathrm{n}^{\circ} \mathrm{XI}$ (2009).

- “La Ley 34/2010, de 5 de agosto, de modificación de la Ley de Contratos del Sector Público en materia de recursos y su incidencia en Castilla-La Mancha", Revista Jurídica de Castilla-La Mancha, $\mathrm{n}^{\circ} 49$ (2010).

232 - "Las últimas reformas de la LCSP y en especial la Ley 34/2010, de 5 de agosto, de modificación de la LCSP, la Ley de Contratos en los Sectores Especiales y la Ley 
de la Jurisdicción Contencioso Administrativa", Contratación Administrativa Práctica, $\mathrm{n}^{\circ} 102$ (2010).

- La reforma de la Ley de Contratos del Sector Público en materia de recursos. Análisis de la Ley 34/2010, de 5 de agosto, la Ley, Madrid, 2010.

Moreno Molina, J.A. y Domínguez Alonso, A.P., "Suma y sigue, el Real Decreto Legislativo 3/2011, de 14 de noviembre, por el que se aprueba el Texto Refundido de la Ley de Contratos del Sector Público", Diario La Ley, $\mathrm{n}^{\circ} 7772$ (2012).

Muñoz Machado, S., El problema de la vertebración del Estado en España (Del siglo XVIII al siglo XXI), lustel, Madrid, 2006.

- Derecho Público de las Comunidades Autónomas, Tomo I, 2 ${ }^{\mathrm{a}}$ ed., lustel, Madrid, 2007.

- Tratado de Derecho Administrativo y Derecho Público General, Tomo III, lustel, Madrid, 2009.

Parejo Alfonso, L., "La revisión especial de actos en la legislación de contratos del sector público", El nuevo marco de la contratación pública (Parejo, L. y Palomar, A., Dirs.), Bosch, Barcelona, 2012.

Palomar Olmeda, A., "La nulidad de los contratos y la nueva acción de nulidad", EI nuevo marco de la contratación pública (Parejo, L. y Palomar, A., Dirs.), Bosch, Barcelona, 2012.

- Derecho de la Función Pública. Régimen jurídico de los funcionarios públicos, $9^{\mathrm{a}}$ ed., Dykinson, Madrid, 2011

Pulido Quecedo, M., El Nuevo Tribunal Administrativo Central de Recursos Contractuales, Aranzadi Thomson Reuters, Navarra, 2010.

Razquin Lizarraga, M.M., "El sistema especial de recursos en la contratación pública tras la reforma de la Ley de Contratos del Sector Público", Revista General de Derecho Administrativo, $\mathrm{n}^{\circ} 25$ (2010). 
